\title{
A Model for Offshore Information Systems Outsourcing Provider Selection in Developing Countries
}

\author{
Philbert Nduwimfura ${ }^{1} \&$ Jianguo Zheng $^{1}$ \\ ${ }^{1}$ Glorious Sun School of Business and Management, Donghua University, Shanghai, China \\ Correspondence: Philbert Nduwimfura, Glorious Sun School of Business and Management, Donghua University, \\ 1882 West Yan An Road, Shanghai, 200051, China. Tel: 86-138-1846-1281. E-mail: mfura@ hotmail.com
}

Received: April 15, 2015

Accepted: May 4, 2015

Online Published: June 25, 2015

doi:10.5539/ibr.v8n7p68

URL: http://dx.doi.org/10.5539/ibr.v8n7p68

\begin{abstract}
Information systems outsourcing has become one of the most important aspects of strategic management. It is becoming the rule, rather than the exception in today's globalized business environment. Many countries and regions have done numerous reforms to become the best offshore information systems outsourcing destinations in the world. For a long time, developing countries remained outside of this competition, but recently the trend has been changing. More developing countries are positioning themselves as viable alternatives to the traditional offshore destinations like India, Ireland and Czech Republic. Selecting an outsourcing provider is a daunting, delicate and very important task for organizations, and can be the cause of an outsourcing failure if not properly addressed. This paper proposes a model based on PROMETHEE (Preference Ranking Organization Method for Enrichment Evaluation) for selecting the best offshore information systems outsourcing provider among a list of developing countries. A case study of 8 African countries is presented in the last part of the paper to illustrate the model. Our model differs from others as it deals with the provider selection problem at country level while most of the existing models deal with the problem at firm level. Another particularity of this model is the set of criteria chosen to analyze the suitability of a country for being the right offshore information systems outsourcing destination.
\end{abstract}

Keywords: decision making, developing countries, information systems outsourcing, offshore outsourcing, provider selection

\section{Introduction}

According to Gartner (2010), many organizations that choose to move IT services to lower-cost countries are daunted by the task of determining which country or countries would best host their operations. This paper's main contribution is to provide organizations with a model that can help them select the most suitable country for their outsourced operations. The importance of developing countries as outsourcing destination was evidenced by Ian Marriot (2010), research vice president at Gartner, who stated that for that year, the top 30 outsourcing destination countries were exclusively emerging nations. He added that as the pace of change was slower in developed countries, they have chosen to focus on those locations that are still maturing and developing, domestically and internationally.

The practice of offshore information systems (IS) outsourcing is increasingly becoming a norm for all major global firms. Consequently, offshore outsourcing has been growing at a very fast annual rate for a few years now. It was expected to reach a growth rate of $20 \%$ from 2009 to 2014 (International Trade Forum, 2010), and in 2012 offshore outsourcing revenues reached $\$ 85$ billion. According to Gartner, the most significant growth opportunities for business in 2013 were located in the so-called emerging, developing, or advancing markets (Gartner, 2013).

The main motivation for firms to engage in offshore IS outsourcing is the creation of value through outsourcing part or all of their IS functions to external providers. A research by the Gartner Group found that the Top 30 countries for offshore services for the year 2010-2011 were emerging nations (Gartner, 2010). In this report, India remained the leader in offshore services while China was the challenger in terms of potential scale. Africa saw four of its countries move into the Top 30, namely Egypt, Morocco, Mauritius and South Africa. This was a result of a significant emphasis on IT and business process services placed by emerging countries as a way of economic growth. On the contrary, 7 developed countries moved out of the Top 30 that year. These included 
Australia, Canada, Ireland, Israel, New Zealand, Singapore and Spain. Although most previous research on offshore IS outsourcing destinations ignored Africa for the most part, it is becoming more evident that this continent is also catching up very fast to become one of the most attractive regions for IS outsourcing.

This proposed model is more suitable for developing countries because they present very incomparable criteria. They may be very good on one criterion, and at the same time be very bad on other Criteria. In such situations, it becomes difficult to make a rational choice, thus the choice of PROMETHEE method which has the ability to effectively manage incomparability and compensatory effects. One such example in our case study is Kenya that performed very well for the criterion internet \& telephony competition (affordability) but performed very badly on other criteria such as the number of procedures needed to enforce a contract (political and regulatory environment). We therefore argue that among all provider selection methods, PROMETHEE-based models are the most suitable for developing countries.

It the following paragraphs, the terms provider and supplier are used interchangeably.

\section{Literature Review}

Selecting an IS outsourcing provider or supplier is a multi-criteria decision making problem. It is often referred to as the provider selection problem. In most cases, the provider selection process is dealt with empirically. Various authors have contributed different approaches used to tackle this problem. Ho et al. (2010) reviewed the literature of the multi-criteria decision making approaches for supplier evaluation and selection. They concluded that the multi-criteria decision making approaches are better than the traditional cost-based approach.

Some authors advocated the use of multi-objective models for the supplier selection problem (Feng et al., 2011). Ho et al. (2011) proposed a decision method for selecting a pool of suppliers for the selection of different service process/product elements. They advocated the use of collaborative utility between partner firms for supplier selection and proposed a multi-objective model for supplier selection. Wadhwa and Ravindran (2007) modeled the vendor selection problem as a multi-objective optimization problem, and then proposed a method combining weighted objective, goal programming and compromise programming.

Other researchers suggested the use of fuzzy methodologies for outsourcing provider selection (Chen et al., 2011; Li et al., 2014; Araz et al., 2007). Wang et al. (2008) proposed fuzzy PROMETHEE method for evaluating IS outsourcing suppliers. Rouyendegh and Saputro (2014) provided an overview of fuzzy TOPSIS (Technique for Order of Preference by Similarity to Ideal Solution) and Multi-Choice Goal Programming methods for multi-criteria decision making problems under uncertain environments.

AHP (analytic hierarchy process) and PROMETHEE methods have also been often used to solve the supplier/provider selection problem. Kahraman and Kaya (2010) advocated the use of AHP for solving multi-criteria decision problems. Wang and Yang (2007) proposed a hybrid model combining AHP and PROMETHEE for making IS outsourcing decisions. Chang et al. (2012) analyzed the problem of selecting an outsourcing provider for SMEs (Small and Medium-Sized Enterprises) in Taiwan, and provided a model based on AHP method. Dulmin and Mininno (2003) highlighted the aspects that are crucial to process qualitative and quantitative performance measures and investigated the contributions of multi-criteria decision-aid method PROMETHEE/GAIE.

Yang and Huang (2000) argued that five factors including management, strategy, technology, economics and quality should be considered for outsourcing decision.

Most of the aforementioned authors dealt with the provider selection problem at the firm level. In our case we approached the problem differently, emphasizing the need to analyze the problem at country level, especially in the case of offshore IS outsourcing. For the given target of developing countries, we believe that our set of twelve criteria is the most comprehensive set of provider selection criteria. It combines all factors that should be considered for the evaluation of an IS outsourcing destination among a set of developing countries. Another shortcoming of some of the aforementioned methods is that they only consider homogenous evaluation criteria (real numbers or linguistic variables only) while our approach is heterogeneous and can easily accommodate both types.

A clear difference with existing methods is that most of them are designed to deal with the provider selection problem at firm level (selecting a provider between different firms), while the model we are proposing is to be used at country level, when comparing which country among a set of countries is the most suitable candidate for information systems outsourcing. This is important because when an organization decides to outsource some or all of its information systems functions offshore, before selecting a provider (firm), first they need to select which country would be more suitable for their operations among a set of different candidates. This proves that the 
provider selection problem should not only be analyzed at firm level, but also at country level if we want to obtain better outcomes from the outsourcing experience.

\section{Information Systems Outsourcing Provider Selection Problem}

Selecting an outsourcing provider is one of the most important tasks of the IS outsourcing process and a critical factor of the success or failure of the outsourcing endeavor. Selecting the best provider for a firm is not a simple task; it is a rather long and difficult process that requires meticulous preparations. The outsourcing process is mainly divided into three phases: the pre-outsourcing, the outsourcing and the post-outsourcing phases (Al-Ahmad \& Al-Oqaili, 2013). Activities related to the provider selection process happen during the first and second phases.

Before selecting a provider, a firm engaging in outsourcing must identify which activities it is going to outsource. Based on those activities, a list of potential providers is established, and then follows the bidding and selection of the best candidate who meets the firm's requirements.

Although the ideal situation for a firm would be to find a provider who is best on all the criteria at the same time, it is almost impossible to find such a provider, thus the provider selection problem becomes a multi-criteria decision problem. A provider may perform well on some criteria but fail on others. The way around this is to choose the best compromise solution. Our suggested model can successfully address this problem thanks to the compensatory effects and the ability to manage incomparability provided by PROMETHEE methods.

Some of the most important criteria for provider selection include costs, technical skills, quality, reliability, lead-time, financial performance, flexibility, reputation, market presence, experience, etc.

Methodologies that are often used for provider selection include Cost Theory, Analytical Hierarchy Process (AHP) and Multiple Attribute Utility Theory (MAUT) (Chen et al., 2011).

\section{A Model for Information Systems Outsourcing Provider Selection}

\subsection{Overview of the PROMETHEE Method}

PROMETHEE (Behzadian et al., 2010) is a multi-criteria decision aid method developed at the ULB and VUB universities in Brussels. PROMETHEE stands for Preference Ranking Organization METHod for the Enrichment of Evaluation. It has been widely used to solve different multi-criteria decision making problems. Common applications of PROMETHEE methods include the evaluation of different decisions presenting several often conflicting criteria, the identification of the best solution or alternative, the ranking of solutions from the best to the worst, sorting items into predefined classes, presenting a better understanding of difficulties surrounding the process of decision making, reaching a consensus decision under the presence of different decision makers who have different conflicting points of view, the justification or invalidation of bad decisions based on objective elements. The PROMETHEE methodology relies on the definition of preference functions and weights to model the preference and priorities of the decision maker.

The PROMETHEE methods are designed to analyze data within a multi-criteria table including a number of actions and several criteria. In mathematical terms, the problem is the following:

$$
\max \left\{f_{1}(a), f_{2}(a), \ldots, f_{j}(a), \ldots, f_{k}(a) \mid a \in A\right\}
$$

Where $\mathrm{A}$ is a finite set of $n$ actions and $f_{l}$ to $f_{k}$ are $k$ criteria, $f_{j}(a)$ is the evaluation of action $a$ on criterion $f_{j}$. The evaluation of the actions on the criteria forms a two-way multi-criteria table (Table 1):

Table 1. Actions evaluation table

\begin{tabular}{ccccccc}
\hline & $f_{l}$ & $f_{2}$ & $\ldots$ & $f_{j}$ & $\ldots$ & $f_{k}$ \\
\hline$a_{1}$ & $f_{l}\left(a_{1}\right)$ & $f_{2}\left(a_{1}\right)$ & $\ldots$ & $f_{j}\left(a_{1}\right)$ & $\ldots$ & $f_{k}\left(a_{1}\right)$ \\
$a_{2}$ & $f_{l}\left(a_{2}\right)$ & $f_{2}\left(a_{2}\right)$ & $\ldots$ & $f_{j}\left(a_{2}\right)$ & $\ldots$ & $f_{k}\left(a_{2}\right)$ \\
$\vdots$ & $\vdots$ & $\vdots$ & & $\vdots$ & & $\vdots$ \\
$a_{i}$ & $f_{l}\left(a_{i}\right)$ & $f_{2}\left(a_{i}\right)$ & $\ldots$ & $f_{j}\left(a_{i}\right)$ & $\ldots$ & $f_{k}\left(a_{i}\right)$ \\
$\vdots$ & $\vdots$ & $\vdots$ & & $\vdots$ & & $\vdots$ \\
$a_{n}$ & $f_{l}\left(a_{n}\right)$ & $f_{2}\left(a_{n}\right)$ & $\ldots$ & $f_{j}\left(a_{n}\right)$ & $\ldots$ & $f_{k}\left(a_{n}\right)$ \\
\hline
\end{tabular}


The decision maker is expected to select the best (optimal) action on all criteria and at the same time. This is a very difficult task especially because of the presence of conflicting criteria. Multi-criteria decision methods like PROMETHEE help in identifying the best compromise decision.

The outranking method PROMETHEE is based on the principle of pairwise comparison of the alternatives (actions) which is done by computing a multi-criteria preference index in the following way:

$$
\pi(a, b)=\sum_{j-1}^{k} W_{j} \times P_{j}(a, b)
$$

Where:

- $w_{j}>0$ is the normalized weight allocated to criterion $f_{j}$ (the more important $f_{j}$ the larger $w_{j}$ ),

- $\quad P_{j}(a, b)$ is the value of the preference function for criterion $f_{j}$ when action $a$ is compared to action $b$.

With normalized weights, $\pi(\mathrm{a}, \mathrm{b})$ is a number between 0 and 1 . It expresses how much $a$ is preferred to $b$ taking into account all the criteria and their weights. For instance:

- if $\pi(a, b)=0$ :

All the $P_{j}(a, b)$ values are equal to 0 which means that $a$ is never even slightly preferred to $b$ on any criterion.

- $\quad$ if $\pi(\mathrm{a}, \mathrm{b})=1$ :

All the $P_{j}(a, b)$ values are equal to 1 which means that $a$ is strongly preferred to $b$ on all the criteria.

So that:

- $\pi(a, b) \approx 0$ means that there is a weak preference for $a$ over $b$.

- $\pi(a, b) \approx 1$ means that there is a strong preference for $a$ over $b$.

The following properties hold:

$$
\left\{\begin{array}{c}
\pi(a, a)=0 \\
0 \leq \pi(a, b) \leq 1 \\
0 \leq \pi(a, b)+\pi(b, a) \leq 1
\end{array}\right.
$$

The benefit of outranking methods is that they are based on a more familiar way of thinking. They don't try to define what is good or bad, but instead, they compare one solution to another. They model the way a decision maker proceeds while comparing two actions without requiring to define what is good and what is bad. They use results from the pairwise comparison of different alternatives to establish a relative ranking of these alternatives from the best to the worst. PROMETHEE methods have the ability to manage incomparability, which is of great contribution to our model.

\subsection{A PROMETHEE Based Model for Selecting the Best Offshore IS Outsourcing Provider in Developing Countries: Case Study}

It has been proved that for information systems outsourcing projects to be successful, there is a need for better and proper provider evaluation and selection. If this step is poorly done, it can have a bad influence on the whole outsourcing endeavor, leading to outsourcing failure.

In this paper, we propose a model for selecting the best IS outsourcing destination country through a case study of selecting the best IS outsourcing provider among eight African countries (Figure 1). Recently, we have been witnessing a rapid growth of IS outsourcing market in Africa (Nduwimfura \& JianGuo, 2014).

The problem of selecting an outsourcing provider/supplier is a multi-criteria decision making problem (Dağdeviren \& Metin, 2008; Gonzalez et al., 2010; Tjader et al., 2010). When dealing with problems with conflicting criteria, using multi-criteria decision making methods (MCDM) is highly recommended. Criteria are said to be conflicting when it is impossible to have optimal values for all the criteria simultaneously. There can be an infinite number of efficient solutions for a MCDM problem. The objective is to find the best compromise solution, which is the efficient solution that is best with respect to the decision maker's preferences (Wadhwa \& Ravindran, 2007).

Eight African countries are considered for this case study; each major region (north, south, east, and west) is represented by two countries. Countries considered in this study are Egypt and Morocco for North Africa, 
Nigeria and Ghana for West Africa, Ethiopia and Kenya for East Africa, and finally South Africa and Namibia for the South African region.

12 criteria related to IT environment in each country are considered for this model: political and regulatory environment, business and innovation environment, infrastructure and digital content, affordability, skills, individual usage, business usage, government usage, economic impact, social impact, language skills and labor availability. These criteria have been chosen according to the World Economic Forum's evaluation of countries in terms of global competitiveness in their Global Information Technology Report 2013. The report featured the latest results of NRI (networked readiness index) by offering a global view of the state of ICT readiness in the world.

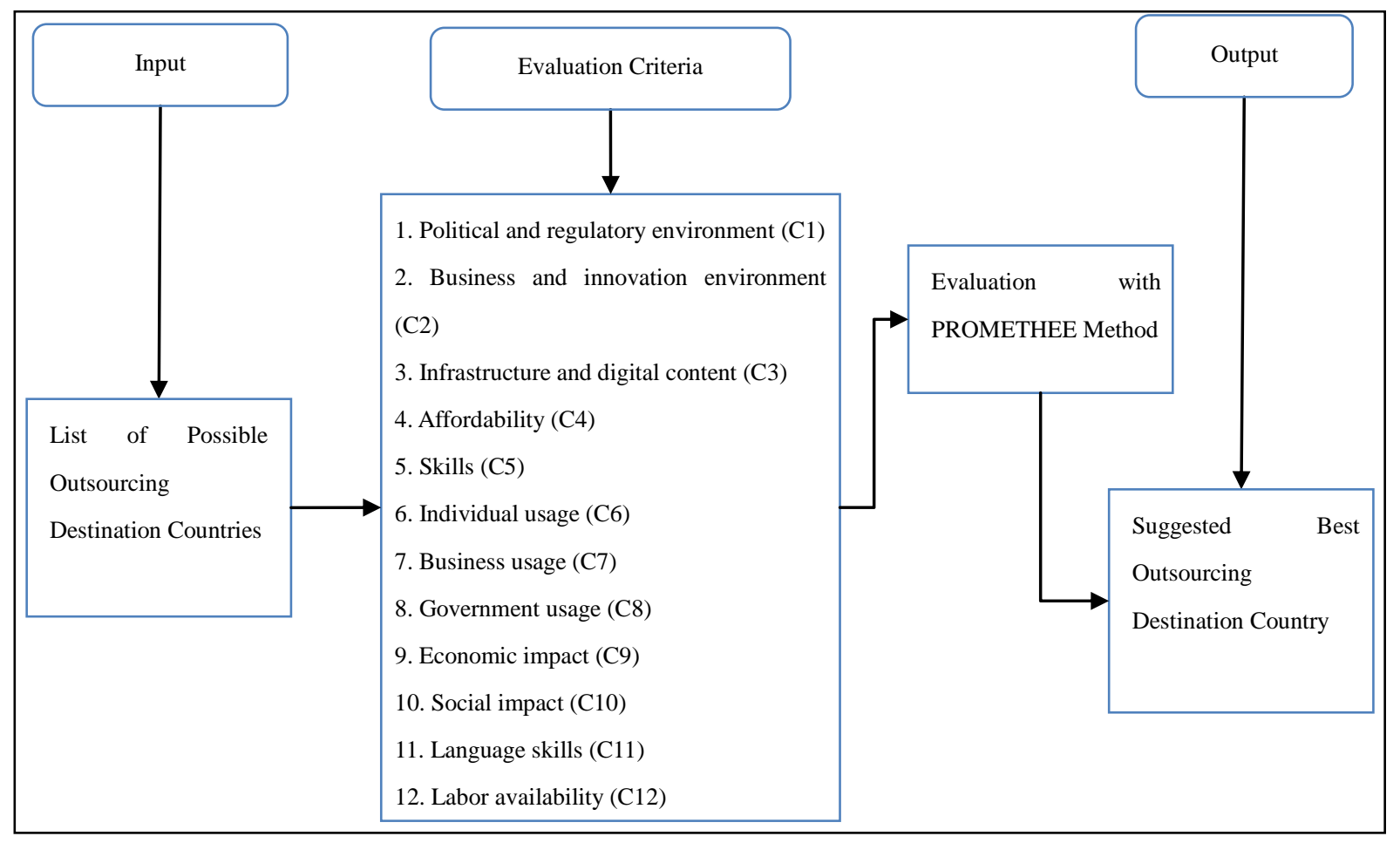

Figure 1. IS outsourcing provider selection model

The data used in this study are obtained from two of the world's renowned institutions which are the World Bank and the World Economic Forum (Bilbao-Osorio et al., 2013).

There are four steps to solving our provider selection problem using PROMETHEE method:

i. Establish a list of potential alternative solutions to the problem: in our case, a list of possible offshore IS outsourcing destination countries.

ii. Define criteria based on which those alternatives are to be evaluated.

iii. Determine the weight of criteria and the preference functions.

iv. Evaluate the performance of each alternative (in our case each of the eight countries) using the PROMETHEE method.

The weight of a criterion is a positive number that represents the criterion relative importance. They are always automatically normalized so that their sum is equal to $1(100 \%)$. The preference function defines how pairwise evaluation differences are translated into degrees of preference.

Our experiment is performed using Visual PROMETHEE 1.4.0.0 and the results are shown in the following paragraphs. The numbers in Table 2 are the average of each country's ranking and performance according to different criteria as presented by (Bilbao-Osorio et al., 2013).

The preference function chosen for this experiment is V-shape for all the criteria except the criteria labor 
availability for which the linear preference function is more appropriate. V-shape preference function is the most appropriate for quantitative criteria.

Table 2. Countries' criteria evaluation

\begin{tabular}{lcccccccc}
\hline Countries & & & & & & & \\
C1 & Egypt & Ethiopia & Ghana & Kenya & Morocco & Namibia & Nigeria & South Africa \\
\hline C2 & 92.22 & 81.62 & 66.25 & 78.00 & 72.44 & 42.75 & 77.33 & 29.66 \\
C3 & 82.88 & 99.33 & 76.77 & 83.55 & 65.00 & 92.66 & 85.00 & 56.11 \\
C4 & 89.20 & 130.20 & 118.40 & 105.80 & 89.20 & 80.80 & 114.60 & 58.00 \\
C5 & 40.66 & 94.00 & 66.33 & 45.66 & 38.00 & 98.33 & 74.66 & 108.00 \\
C6 & 123.00 & 114.50 & 95.50 & 79.75 & 100.25 & 113.00 & 105.25 & 108.00 \\
C7 & 67.14 & 136.85 & 102.14 & 111.71 & 65.42 & 94.00 & 100.00 & 79.14 \\
C8 & 93.00 & 131.33 & 100.16 & 69.16 & 85.66 & 76.66 & 79.83 & 39.16 \\
C9 & 85.33 & 79.66 & 79.66 & 47.66 & 67.33 & 103.00 & 90.33 & 94.66 \\
C10 & 72.00 & 108.75 & 89.33 & 57.66 & 87.50 & 103.50 & 71.33 & 49.25 \\
C11 & 82.25 & 94.00 & 97.75 & 76.25 & 97.00 & 114.00 & 82.50 & 101.75 \\
C12 & 2.00 & 2.00 & 1.00 & 2.00 & 3.00 & 3.00 & 1.00 & 2.00 \\
\hline
\end{tabular}

\section{Results Discussion}

This study contributes to the theory of IS outsourcing by providing a different approach of outsourcing provider evaluation at country level based on a combination of qualitative and quantitative criteria. It helps to evaluate the competitiveness of an alternative outsourcing destination country based on the general economic, political, technological and social environment of the country.

Here are the Phi, Phi+ and Phi- scores computed using PROMETHEE I and PROMETHEE II methods for the eight countries (Table 3). These scores are used for the ranking of different alternatives: the higher Phi or Phi+ is, the better the alternative, the lower Phi- is, the better the alternative. The table shows the ranking of the eight countries from the best to the worst offshore IS outsourcing destination according to PROMETHEE I and PROMETHEE II methods.

Table 3. Actions' Phi, Phi+ and Phi- scores

\begin{tabular}{ccccc}
\hline Ranking & Country & Phi & Phi+ & Phi- \\
\hline 1 & Morocco & 0.3101 & 0.6235 & 0.3134 \\
2 & Kenya & 0.2450 & 0.5768 & 0.3318 \\
3 & South Africa & 0.2028 & 0.5668 & 0.3641 \\
4 & Egypt & 0.0132 & 0.4528 & 0.4396 \\
5 & Nigeria & -0.0311 & 0.4501 & 0.4812 \\
6 & Ghana & -0.0488 & 0.4470 & 0.4958 \\
7 & Namibia & -0.2247 & 0.3652 & 0.5899 \\
8 & Ethiopia & -0.4666 & 0.2258 & 0.6924 \\
\hline
\end{tabular}

It can be seen that based on Phi scores, the best country for offshore information systems outsourcing among the eight countries is Morocco which has the highest Phi score (Table 3 \& Figure 2), followed by Kenya, then South Africa and Egypt. Four counties have negative Phi values and rank in the bottom. They are respectively Nigeria, Ghana, Namibia and Ethiopia. All major regions have a representative in the top four except West Africa for 
which the two representatives (Nigeria and Ghana) are both in the bottom four. The rankings according to Phi+ or Phi- scores are consistent with that of Phi scores.

The following is the GAIA visual analysis.

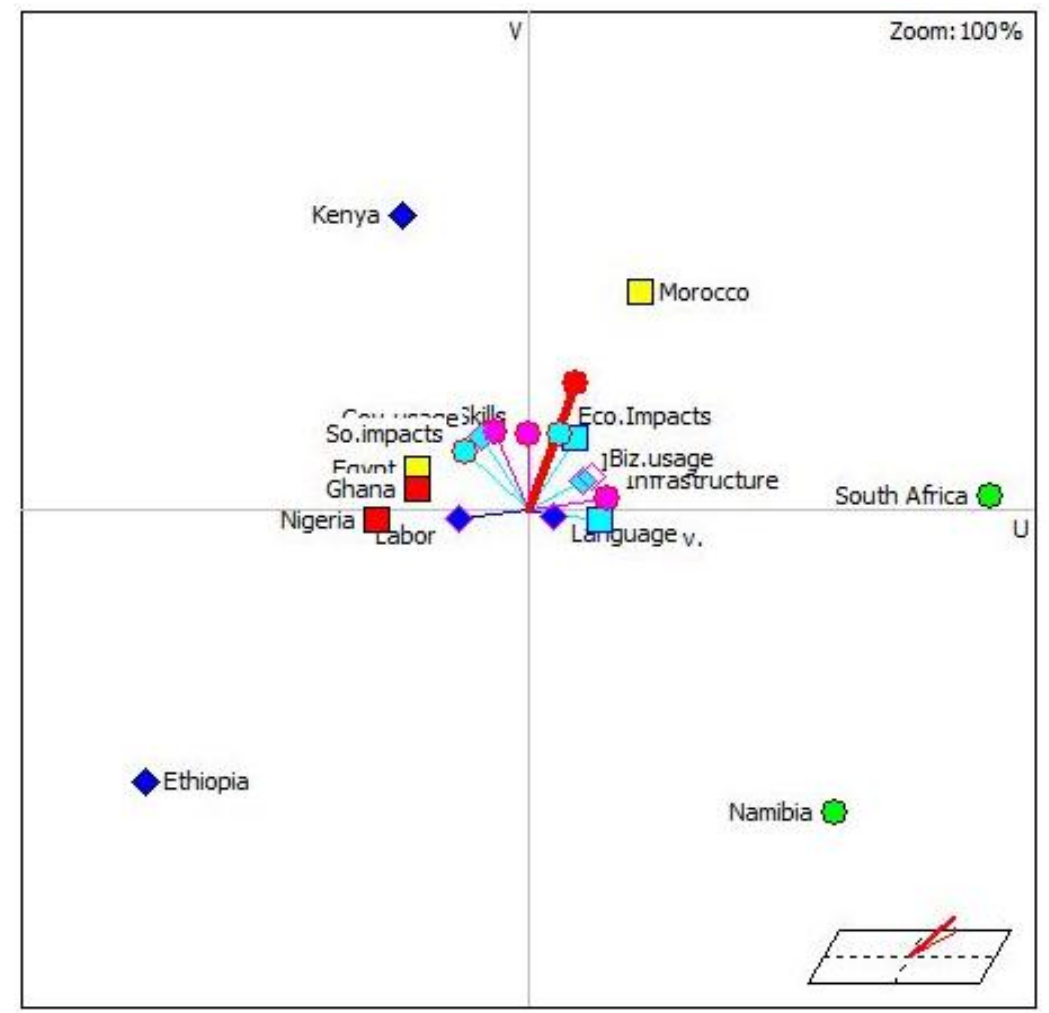

Figure 2. Actions' GAIA visual analysis

In Figure 2, the decision axis is in red and point towards Morocco which is in the same direction as the decision axis: it shows that Morocco is the best alternative. Two countries are far from the decision axis and in the opposite direction; these are the least performing countries of the group, namely Namibia and Ethiopia.

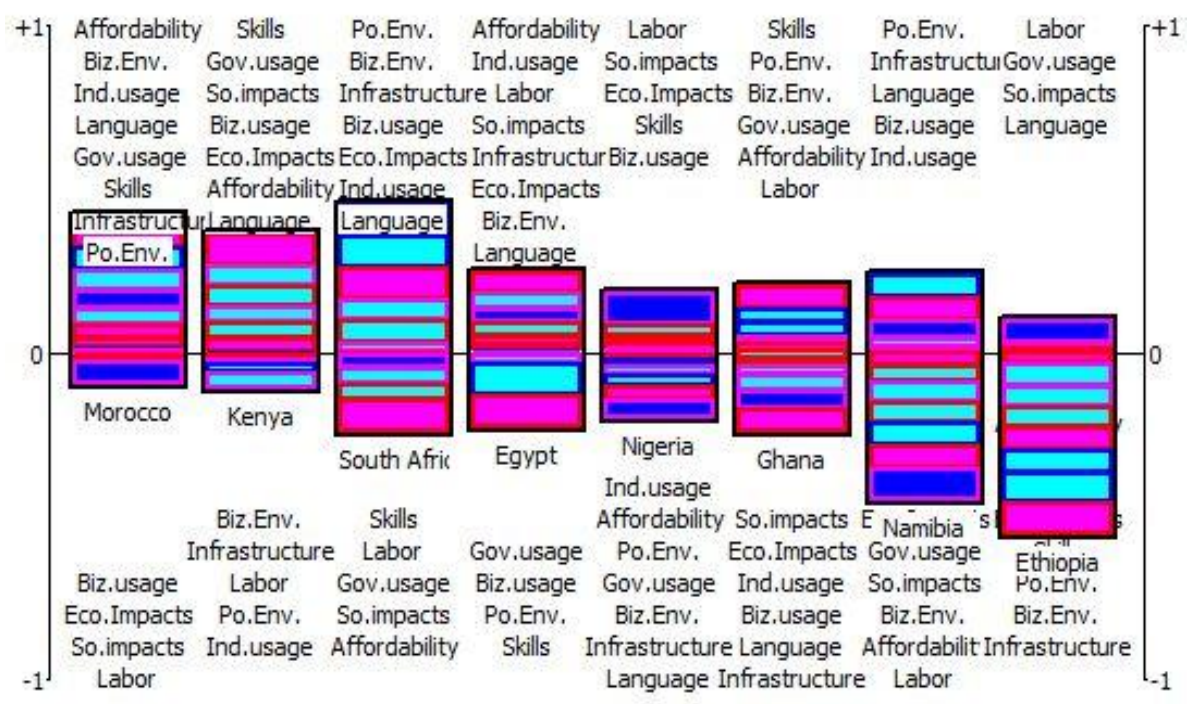

Figure 3. PROMETHEE rainbow 
Based on PROMETHEE Rainbow (Figure 3), Morocco ranked number one performs well on criteria such as affordability, business environment, individual usage, language, government usage, skills, infrastructure and political environment; but it performs poorly on business usage, economic impacts, social impacts and labor.

Kenya ranked number two gets very good scores on skills, government usage, social impacts, business usage, economic impacts, affordability and language. It is poorly ranked for business environment, infrastructure, labor, political environment, and individual usage.

Number three is South Africa which is very well ranked for political and business environment, infrastructure, business and individual usage, economic impacts and language. It doesn't do so well on skills, labor, government usage, social impacts and affordability.

The country ranked number four is Egypt which performs well for criteria such as affordability, individual impact, labor, social and economic impacts, infrastructure, business environment and language. It lags behind on government and business usage, political environment and skills.

Nigeria is good for labor, social and economic impacts, skills and business usage. It is bad on individual and government usage, affordability, political and business environment, infrastructure and language.

Ghana has very good scores on skills, political and business environment, government usage, affordability and labor. It gets bad scores for social and economic impacts, individual and business usage, language and infrastructure.

Second from last, Namibia has a very good political environment, infrastructure, business and individual usage, and language skills. It performs badly on government usage, social impacts, business environment, affordability and labor availability.

The least performing country is Ethiopia which has good scores for labor availability, government usage, social impacts and language skills. Ethiopia performs badly on affordability, individual and business usage, economic impacts, skills, political and business environment and infrastructure.

To the best of our knowledge, the exact set of criteria used in this model has never been used in any other model for the evaluation of an outsourcing provider. We believe that they are the most comprehensive set of criteria which can be used when selecting an offshore outsourcing destination country. In this study, PHOMETHEE method is adopted because as one of the most efficient existing outranking methods, it has the ability to deal with qualitative and quantitative variables and intangible criteria, to effectively manage compensatory effects and incomparability, and understands well relations between criteria.

\section{Conclusions and Recommendations}

Provider selection has been proved to be one of the most critical activities during an outsourcing process. It is one of the most important determinants of the success or failure of the outsourcing process.

In this paper, we provided a model for selecting an offshore information systems provider based on PROMETHEE methods. An example involving eight African countries in the choice of the best offshore IS provider in Africa was described.

It is evident that for information systems outsourcing to be successful, there is a need for better and proper provider evaluation and selection.

We argue that PROMETHEE methods are very well suited for dealing with offshore provider selection problems occurring during information systems outsourcing process. The main reason is their ability to deal with qualitative and quantitative criteria at the same time, therefore providing a best compromise solution.

Our model is based on a set of criteria that, to the best of our knowledge, has never been used in any previous IS outsourcing provider selection model. The evaluation criteria in this model provide a comprehensive view of an offshore IS outsourcing provider.

\section{Acknowledgement}

This research work was supported by National Natural Science Foundation of China under Grant No. 70971020.

\section{References}

Adelakun, O., \& Iyamu, T. (2013). Offshore IT outsourcing to South Africa-analysis of readiness and attractiveness. http://dx.doi.org/10.1057/jit.2008.17

Araz, C., Mizrak Ozfirat, P., \& Ozkarahan, I. (2007). An integrated multicriteria decision-making methodology for outsourcing management. Computers \& Operations Research, 34(12), 3738-3756. 
http://dx.doi.org/10.1016/j.cor.2006.01.014

Behzadian, M., Kazemzadeh, R. B., Albadvi, A., \& Aghdasi, M. (2010). PROMETHEE: A comprehensive literature review on methodologies and applications. European Journal of Operational Research, 200(1), 198-215. http://dx.doi.org/10.1016/j.ejor.2009.01.021

Bilbao-Osorio, B., Dutta, S., \& Lanvin, B. (2013). The global information technology report 2013. World Economic Forum.

Chang, S. I., Yen, D. C., Ng, C. S. P., \& Chang, W. T. (2012). An analysis of IT/IS outsourcing provider selection for small-and medium-sized enterprises in Taiwan. Information \& Management, 49(5), 199-209. http://dx.doi.org/10.1016/j.im.2012.03.001

Chen, Y. H., Wang, T. C., \& Wu, C. Y. (2011). Strategic decisions using the fuzzy PROMETHEE for IS outsourcing. Expert Systems with Applications, $38(10), \quad$ 13216-13222. http://dx.doi.org/10.1016/j.eswa.2011.04.137

Dağdeviren, M. (2008). Decision making in equipment selection: An integrated approach with AHP and PROMETHEE. Journal of Intelligent Manufacturing, $397-406$. http://dx.doi.org/10.1007/s10845-008-0091-7

Dulmin, R., \& Mininno, V. (2003). Supplier selection using a multi-criteria decision aid method. Journal of Purchasing and Supply Management, 9(4), 177-187. http://dx.doi.org/10.1016/s1478-4092(03)00032-3

Feng, B., Fan, Z. P., \& Li, Y. (2011). A decision method for supplier selection in multi-service outsourcing, in International Journal of Production $\quad$ Economics, $\quad 132(2), \quad 240-250$. http://dx.doi.org/10.1016/j.ijpe.2011.04.014

Gonzalez, R., Gasco, J., \& Llopis, J. (2010). Information systems offshore outsourcing: An exploratory study of motivations and risks in large Spanish firms. Information Systems Management, 27(4), 340-355. http://dx.doi.org/10.1080/10580530903455205

Ho, W., Xu, X., \& Dey, P. K. (2010). Multi-criteria decision making approaches for supplier evaluation and selection: A literature review. European Journal of Operational Research, 202(1), 16-24. http://dx.doi.org/10.1016/j.ejor.2009.05.009

Kahraman, C., \& Kaya, İ. (2010). A fuzzy multicriteria methodology for selection among energy alternatives. Expert Systems with Applications, 37(9), 6270-6281. http://dx.doi.org/10.1016/j.eswa.2010.02.095

Li, D. F., \& Wan, S. P. (2014). Fuzzy heterogeneous multiattribute decision making method for outsourcing provider selection. Expert Systems with Applications, 41(6), 3047-3059. http://dx.doi.org/10.1016/j.eswa.2013.10.036

Nduwimfura, P., \& Zheng, J. G. (2014). The present and future of information systems outsourcing in Africa (pp. 591-595). 2014 International Conference on Computer, Network Security and Communication Engineering (CNSCE), DEStech Publications, Inc.

Saputro, T. E. (2014). Supplier selection using integrated fuzzy TOPSIS and MCGP: A case study. Procedia-Social and Behavioral Sciences, 116, 3957-3970. http://dx.doi.org/10.1016/j.sbspro.2014.01.874

Tjader, Y. C., Shang, J. S., \& Vargas, L. G. (2010). Offshore outsourcing decision making: A policy-maker's perspective. European Journal of Operational Research, 207(1), 434-444. http://dx.doi.org/10.1016/j.ejor.2010.03.042

Wadhwa, V., \& Ravindran, A. R. (2007). Vendor selection in outsourcing. Computers \& Operations Research, 34(12), 3725-3737. http://dx.doi.org/10.1016/j.cor.2006.01.009

Wang, J. J., \& Yang, D. L. (2007). Using a hybrid multi-criteria decision aid method for information systems outsourcing. Computers \& Operations Research, 34(12), 3691-3700. http://dx.doi.org/10.1016/j.cor.2006.01.017

Wang, T. C., Chen, L. Y., \& Chen, Y. H. (2008). Applying fuzzy PROMETHEE method for evaluating IS outsourcing suppliers. Fuzzy Systems and Knowledge Discovery. FSKD'08. Fifth International Conference. 3, 361-365. http://dx.doi.org/10.1109/fskd.2008.506

Yang, C., \& Huang, J. B. (2000). A decision model for IS outsourcing. International Journal of Information Management, 20(3), 225-239. http://dx.doi.org/10.1016/s0268-4012(00)00007-4 


\section{Copyrights}

Copyright for this article is retained by the author(s), with first publication rights granted to the journal.

This is an open-access article distributed under the terms and conditions of the Creative Commons Attribution license (http://creativecommons.org/licenses/by/3.0/). 